\title{
Data Analytics and Knowledge Integration Mechanisms: The Role of Social Interactions in Innovation Management
}

\author{
Giorgi Shuradze \\ European University Viadrina \\ shuradze@europa-uni.de
}

\author{
Heinz-Theo Wagner \\ German Graduate School of Management and Law \\ heinz-theo.wagner@ggs.de
}

\begin{abstract}
In a firm, which is viewed as a distributed knowledge system, the role of knowledge integration mechanisms is critical. In the context of data analytics, data mining and statistical analysis enables firms to generate knowledge; which, however, needs to be channeled to the end user of this knowledge. In this study, based on the social capital literature we argue that social interactions between IT and marketing functional unit members facilitate knowledge sharing in intraorganizational setting, which in turn results in improved innovative performance. The theoretical arguments are supported by empirical results collected via an online survey. Theoretical and practical contributions of the study are also discussed.
\end{abstract}

\section{Introduction}

A view of a firm as a distributed knowledge system [1], challenges managers with the strategic task of coordinating the channels of knowledge flows from the knowledge provider to the knowledge seeker [2, 3]. In the context of data analytics, which is a data mining and statistical analysis techniques, this view is particularly valuable because data analytics is an important antecedent of knowledge that sources competitive advantage and is a key for innovation strategies in the digital economy [4-8].

In a general sense, the ability of a company to leverage information technology (IT) resources in business practices critically depends on the interaction between IT and business units [9]. Accordingly, while data analytics has a potential to provide data driven insights that are crucial for competitive advantage [4, $6,7]$, it is only business units that are in position of effectively utilizing this knowledge to take advantage of business opportunities [9].
The novelty of data analytics topic necessitates new norms and practices to be established on how to successfully tackle the challenges of the field [64]. It is because of the novelty of this literature [5-7] that research on data analytics is mostly rooted in its technological traditions. In such ways the extent research tackles only separate parts of the phenomenon in isolation; whereas leaving other relevant elements, such as the mechanisms of transferring knowledge, i.e. the means by which organizations share knowledge internally [10], from data analytics into business units insufficiently explored.

Therefore, in this work we address this void in the literature and empirically explore the nature of this strategically important, yet overlooked, knowledge integration mechanism. In addition, we examine the extent to which the technical aspects of data analytics as well as the knowledge integration mechanism affect organizations' innovative performance in the digital economy. Hence, we propose the following research question for exploration: what is the knowledge integration mechanism in data analytics research, and to what extent does it affect the innovative performance of a firm?

To answer this research question, in this study we depart from the traditional realm of data analytics research that has roots in technological perspective and combine the research on data analytics with the stream of literature that views social communications as a mean of knowledge exchange, i.e. social capital literature $[11,12]$. Particularly, following the knowledge-based view [3, 13, 14] we argue that, because it is communication processes that drive knowledge transfer in organizations [15], successful application of data driven insights, extracted by the IT functional units, requires transfer of these insights to the end user of this resource, i.e. marketing functional unit. As a channel for these insights, based on social capital literature, we propose intraorganizational social relationships between IT and marketing units. 
With the results of this paper we make several key contributions. First, by proposing the knowledge integration mechanism in data analytics research we contribute to data analytics research [4-8] by identifying the mechanism that facilitates the intraorganizational knowledge exchange, which in turn leads to improved organizational performance. Additionally, the identification also contributes to research on knowledge-based view that seeks further exploration of social, cultural, and technical attributes of organizational settings through which the knowledge flows from the knowledge provider to the knowledge seeker [15].

\section{Theoretical background}

In this section we examine the theoretical aspects that lay a foundation for the constructs employed in our theoretical argumentation. Particularly, this area covers literature on data analytics, social capital, and the two types of innovations.

\subsection{Data analytics}

Data analytics is defines as "technologies that are grounded mostly in data mining and statistical analysis" (p. 1174) [6]; and although analytical techniques commonly used in data analytics date back to the 1970s and 1980s, when statistical methods and data mining techniques were first developed, it has been only recently that the practice has regained its momentum in the new and growing context of the digital economy [6]. The cause of this quick shift could be attributed to fast changes in technology and the pace at which interconnected technical devices generate digital data that contain information about human behavior [16].

While it is unanimously agreed that a large amount of digital data has the potential to revolutionize how organizations function and how decisions are made in firms [16-19], it is also apparent that data is not selfexplanatory and that without the application of relevant technology it is nothing but noise [5, 20-23]. Studies with empirical evidence of such technologies range from the usage of supermarket scanner data $[24,25]$ to a powerful set of data analysis, data mining and data visualization tools [26-28]. Luftman et al. [29] further argue that integrated business intelligence systems are the most influential technology in organizations. Accordingly, McAfee and Brynjolfsson [17] identify empirical evidence that adoption of business intelligence systems leads to an organizational productivity increase between $4 \%$ and $6 \%$.

\subsection{Social capital}

The literature on social capital is primarily concerned with the role of social relationships in creation and exchange of knowledge [11]. According to the definition of Nahapiet and Ghoshal (p. 243) [11], social capital is "the sum of the actual and potential resources embedded within, available through, and derived from the network of relationships possessed by an individual or social unit". By providing a shared context for social interactions, social capital facilitates the creation of new linkages in the organizational setting [30], which in turn could stimulate knowledge transfer in intraorganizational networks [31].

Social capital, based on a review of previous research, is conceptualized as a multidimensional construct, comprising: structural social capital, relational social capital, and cognitive social capital $[11,12,30]$. Structural social capital refers to overall patterns of connections between actors, i.e. presence or absence of network ties among entities [11]. This dimension concerns the properties of the social system as a whole, and describes the impersonal configuration of linkages between people and units as well as the frequency of such connections. Put differently, this dimension captures an entity's location in a social network $[11,12,30]$.

Relational social capital, on the other hand, describes the quality of personal relationships that actors of the network have developed with each other through their interactions over time [11]. Among the key characteristics of this dimension are trust/ trustworthiness, appreciation, mutual respect, and reciprocity. In intraorganizational settings, such characteristics among people as well as organizational units constrain opportunistic behaviors among them and increase the willingness to cooperate and exchange resources [30]. Organizational units characterized with trustworthiness and respect are more likely to form intraorganizational strategic linkages with each other that can eventually provide new opportunities for productive resources exchange among them [30].

Cognitive social capital, the third dimension of social capital, is embodied in attributes like a shared code or a shared paradigm that facilitate a common understanding of collective goals and proper ways of acting in a social system [12]. Inside multiunit organizations, shared values and interpretation systems among units help establish and develop relationships between them, which in turn facilitate individual and group actions that can benefit the entire organization. These resources also represent facets of particular importance in the context of our consideration of knowledge exchange, including shared language and codes and shared narratives. 


\subsection{Exploratory and exploitative innovations}

In this paper, we follow previous literature on innovations and categorize them in two fundamentally different modes: exploratory and exploitative innovations [32-34]. Exploratory innovations are radical innovations that target the needs of emerging customers and market segments. Such innovations typically come in new design, they shape new markets, and develop new channels of distribution. According to O'Reilly and Tushman [35] exploration is about search, discovery, autonomy, and embracing variations. Hence, in order to achieve exploratory innovations, organizations often experiment with new ways of approaching extant products/services, markets, and distribution channels. This often requires new knowledge or departure from existing knowledge [36].

On the contrary, exploitative innovations are incremental innovations that are designed to meet the needs of existing customers and markets [33]. Conversely to exploration, exploitation is about efficiency, increasing productivity, control, speed of market, certainty, and variance reduction [35]. Innovations of this nature enhance the design of extant products/services, and increase the efficiency of existing distribution channels [33]. Exploitative innovations involve improvements in existing components and architectures, and are built on the existing technological trajectory; hence they are based on existing knowledge and skills [36]. And while exploitative activities help firms quickly learn and adapt in the short term, the same activities may exacerbate inertia and inhibit experimentation and, in turn, organizational responsiveness to environmental changes [36].

\section{Research model and hypotheses}

In this section we develop theoretical arguments as to why data analytics infrastructure as well as its complementary asset IT-marketing social capital can promote organization's innovative performance, and propose hypotheses for empirical testing. Below we present the research model of the study:

By definition data analytics infrastructure are data analytics technologies that include platforms, software applications as well as data repositories; and frequency of updates to all data analytics-related asset stocks. Conversely to the definition of data analytics, the definition of data analytics infrastructure provides broader, rather extended perspective, uniting data analytics related hardware and software as well as their maintenance. In our conceptualization data analytics infrastructure is a representation of a firm's computational ability that is integrated into a firm's business processes. As a consequence to this multidimensional perspective, data analytics infrastructure incorporates the following two dimensions: analytical ability and IT business process integration. Analytical ability is an organization's analytical ability to recognize patterns as well as extract and interpret insights from large datasets. This ability facilitates understanding of markets, customers' behavior and choices, and detection of changing trends in an organization's environment. According to Chaudhuri et al. [37], this requires technologies such as Extract-Transform-Load tools (ETL), data warehousing, relational Database Management Systems (DBMS), Online Analytical Processing (OLAP), visualization tools, and Hadoop-/MapReducebased systems.

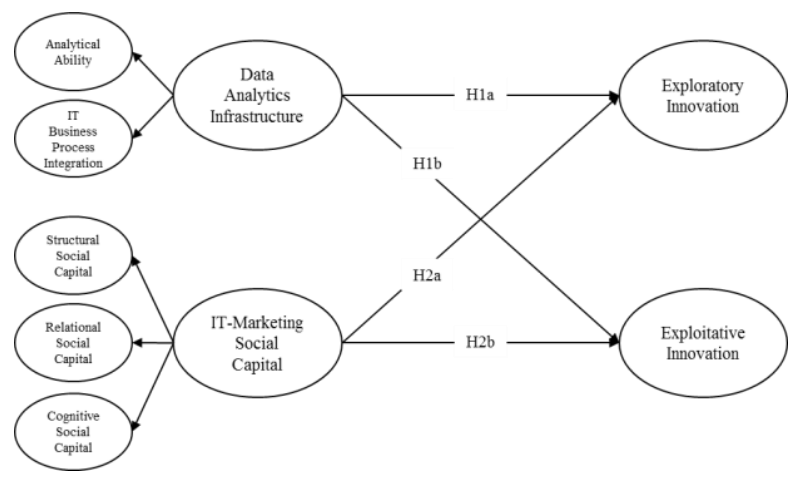

Figure 1. Research model

In contrast, the second dimension of data analytics infrastructure, i.e. IT business process integration, is more concerned with the part of the infrastructure that refers to integrating an organization's analytic ability into business processes for detecting patterns of emerging innovative business opportunities. Scholars agree that in order to serve business purposes, technological tools are expected to be integrated into business processes [38-42]. In this article, we see business processes as iterative sets of activities, that are the means of performing certain organizational tasks as well as ways for storing and accessing knowledge effectively to accomplish tasks that support value creation from analytics tools [43]. And while technology (in its broader sense) and its integration into business processes do not represent the end destination of using data driven knowledge; we argue that it is important first step towards leveraging digital data for innovation purposes, and hence propose the following hypotheses for empirical testing:

Hypothesis 1a (H1a): Data analytics infrastructure has a positive effect on exploratory innovation.

Hypothesis $1 \mathrm{~b}(\mathrm{H} 1 \mathrm{~b})$ : Data analytics infrastructure has a positive effect on exploitative innovation. 
Agreeing on that integrated firm's computational ability can derive insights from digital data resources, brings about the follow up question on how to integrate these insights into knowledge generation and decisionmaking; i.e. how to channel the insights to the end user of this knowledge. In the context of data analytics, we view a marketing functional unit as an end user of this knowledge. This position is based on several arguments: while digital data provides insights on human behavioral patterns, it is marketers that translate these insights into market advantage [44]. In addition, marketing is becoming more personalized; therefore having an access to data that contains records on personal preferences could make the customized offerings more accurate [45]. The view that the insights gained through data analytics are important for various marketing activities is also supported by number of studies [46, 47]. Based on these arguments and the arguments made by earlier studies from the knowledge-based view that an ability of the firm to continually innovate is a function of knowledge creation (i.e. detecting data driven insights) and knowledge integration (i.e. the ability to seize and implement these advances through organizational processes and structures) [48], we posit that knowledge exchange between IT and marketing functional units can facilitate organizations innovative performance.

While formal knowledge transfer mechanisms (e.g. training sessions, and formal communication processes) between knowledge providers and knowledge seekers may ensure greater distribution of knowledge, these mechanisms may inhibit creativity [15]. In the context of innovation management, however, creativity could be seen as a key component. Therefore, instead of formal mechanisms, in this paper we draw on informal knowledge transfer mechanisms between IT (knowledge provider) and marketing (knowledge seeker) units; and propose to look at this relationship through a social capital perspective.

Accordingly, we argue that IT-Marketing social capital, defined as an intangible organizational resource that is reflected in the ability of an IT unit to create partnerships with marketing to work together and exploit new business opportunities, can allow the effective deployment of IT resources in marketing tasks, and that this social partnership will facilitate radical (exploratory) as well as incremental (exploitative) innovations.

Following the social capital literature [11], we conceptualize IT-marketing social capital as a three dimensional construct, comprising: structural, relational, and cognitive social capital. Structural social capital characterizes the presence/absence of social ties among the IT and marketing functional unit members, relational social capital describes the type of these relationships, and cognitive social capital features common language and narrates among these unit members. We argue that once the two units succeed in establishing social ties, developing trust with each other and reach understanding; their interaction will enable knowledge flow, which is likely to positively affect organizations performance. Therefore:

Hypothesis 2a (H2a): IT-Marketing social capital has a positive effect on exploratory innovation.

Hypothesis 2b (H2b): IT-Marketing social capital has a positive effect on exploitative innovation.

\section{Research methodology}

\subsection{Data collection}

We gathered the data for the study through a crosssectional online survey. The population for the survey was firms located in Germany. In order to maximize the generalizability of the findings, we included a broad range of industries and firms. The companies were randomly selected and represented large variance in terms of industry they operated in: manufacturing (SIC code 20-39, $\mathrm{n}=20$ ), transportation and public utilities (SIC code 40-49, $\mathrm{n}=8$ ), wholesale trade (SIC code 50-51, $\mathrm{n}=6$ ), retail trade (SIC code 52-59, $\mathrm{n}=$ 11), finance, insurance, real estate (SIC code 60-67, n $=13$ ), services (SIC code 70-89, $\mathrm{n}=54$ ), and 22 participants did not provide industry information. Furthermore, our sample frame included firms of small, medium and large size: $51(38.3 \%)$ were from small and medium enterprises ( $<250$ employees), 82 (61.7\%) from big firms (> 250 employees), and one participant did not report his/her company size.

The survey was administered through an online questionnaire. The URL of the online survey was sent to companies via the professional networking website Xing.com, which is the largest web-page of its kind in German speaking countries. A background of the study that stated the research objective was first provided to the respondents. The respondents were assured of the confidentiality of their responses and that only aggregated responses would be reported.

We sent a survey link to 2067 business analysts and business developers. We think this is the appropriate target group because these people work on managerial level, interact with the members of IT as well as marketing functional units, and are in position of observing the relationships between these two entities. Of the questionnaires that we sent out, 138 were completed. Among the filled in questionnaires, four were deleted after data screening and identification of missing values. This resulted in 134 usable responses, with a response rate of $7 \%$. This rate is typical for online surveys [49]. 


\subsection{Constructs and measurements}

In this study the construct of data analytics infrastructure and IT-marketing social capital are modeled as second order constructs, composed of two and three dimensions, respectively. The items for the dimensions of the two constructs are based on extant literature and adapted to the context of the research. The two dimensions of data analytics infrastructure are: analytical ability (based on Roberts and Grover [50]) and IT business process integration (based on Bharadwaj et al. [51]). The items for the three dimensions of IT-marketing social capital are adapted from the measurements used by Sun et al. [52]).

To establish construct validity of the newly developed second order constructs, the procedure described by Gerow et al. [53] was carried out. First, the research constructs were operationalized through definitions of the constructs. Second, item pools were generated for the constructs based on their conceptual definition and description. Third, all items were tested for content validity. This included three unique rounds of card sorting, which is considered to be the best method to assess content validity [54]. First two rounds of card sorting process involved three members of academic faculty and seven doctoral students; all with experience of the field. In each round, judges were asked to match the items with the given definitions of the research constructs. After each first two round, items were modified according to the comments and remarks of the judges. The final round of card sorting was conducted with 17 practitioners who were members of an executive study program. In the end, necessary minor modifications were made to the survey instrument based on the final round.

Exploratory innovation and exploitative innovation were measured using the existing validated items from Jansen et al. [33]. Since we had no need to make changes to the items, no construct validation process was carried out for the measurements of these two outcome variables.

All of the measurement items were based on a seven-point Likert scale with 1 equated to "strongly disagree" and 7 equated to "strongly agree". The Appendix at the end of this article shows every construct and their respective measurement items.

\section{Analysis and results}

\subsection{Measurement model}

In our conceptualization we propose a measurement model based on underlying sub-constructs. To test the quality of the newly developed questionnaire we performed exploratory (EFA) and confirmatory factor analysis (CFA) procedure, as suggested by Gerow et al. [53]. We performed an EFA based on the principal component analysis in order to check the quality of the factors without constraining their number. After deleting the items with the lowest factor loadings, we repeated the procedure, which produced a clean pattern matrix. This step was followed by a CFA.

Because our two independent variables are a higher, second-order constructs, we took a two-step approach. First, we performed the initial analysis with only firstorder constructs so that we could discover whether reliability and validity issues were present. In the initial test we checked the Cronbach's alpha, CR, average variance extracted, maximum shared variance, and average shared variance, and we controlled for interfactor correlations. The tested model produced a very good model fit: $\chi^{2} / \mathrm{df}=1.254\left(\chi^{2}=373.614, \mathrm{df}=298\right)$. The root mean square error of approximation (RMSEA) of the model was .044, the Comparative Fit Index (CFI) was 0.97, and the Tucker-Lewis Index (TLI) was 0.965 , supporting the very good model fit [55]. As shown in Table 1, all item loadings are above 0.7 . The composite reliability of all constructs is higher than 0.8 , and the average variance extracted (AVE) values are all greater than 0.5 , indicating convergent validity. So, in the initial model we found no validity and reliability concerns [56-58].

Table 1. Reliability and validity statistics for the first-order constructs

\begin{tabular}{|l|l|l|l|l|l|l|l|l|l|l|}
\hline & $\boldsymbol{\alpha}$ & CR & AVE & MSV & ASV & COGSC & ANABI & ITBPI & STRSC & RELSC \\
\hline COGSC & .897 & .912 & .777 & .345 & .135 & $\mathbf{. 8 8 1} \dagger$ & & & & \\
\hline INABI & .836 & .840 & .638 & .424 & .121 & .094 & $.799 \dagger$ & & & \\
\hline TBPI & .906 & .914 & .727 & .424 & .197 & .275 & .651 & $\mathbf{. 8 5 3} \dagger$ & & \\
\hline TRSC & .927 & .934 & .779 & .334 & .139 & .491 & .033 & .187 & $.883 \dagger$ & \\
\hline RELSC & .873 & .900 & .694 & .345 & .182 & .587 & -.019 & .325 & .578 & $\mathbf{. 8 3 3} \dagger$ \\
\hline
\end{tabular}

Whereby a "i" indicates the average factor loadings, "COGSC" stands for cognitive social capital, "ANABI" for analytical ability, "ITBPI" for IT business process integration, "STRSC" for structural social capital, and "RELSC" for relational social capital.

In our second step of confirmatory factor analysis, we introduced the second-order constructs of data analytics infrastructure and IT-marketing social capital into our CFA. Here we checked if the introduction of second-order constructs would cause any validity or reliability problem. The second model (second-order constructs with underlying reflective first-order 
constructs) showed a very good model fit: $\chi 2 / \mathrm{df}=$ $1.278(\chi 2=394.791, \mathrm{df}=309)$. The root mean square error of approximation of the model was 0.046 , the CFI was 0.966 , and TLI was 0.962 , supporting the very good model fit [55]. The second model, also showed no validity/reliability concerns (see Table 2) [56-58].

\section{Table 2. Reliability and validity statistics for the second-order constructs}

\begin{tabular}{|l|c|c|c|c|c|l|}
\hline & CR & AVE & MSV & ASV & $\begin{array}{l}\text { Data Analytics } \\
\text { Iffastructure }\end{array}$ & $\begin{array}{l}\text { TT- } \\
\text { marketing } \\
\text { locial } \\
\text { Capital }\end{array}$ \\
\hline $\begin{array}{l}\text { Data Analytics } \\
\text { Infrastructure }\end{array}$ & .821 & .705 & .506 & .312 & $\mathbf{. 8 4 0} \dagger$ & \\
\hline $\begin{array}{l}\text { IT-marketing } \\
\text { Social Capital }\end{array}$ & .789 & .558 & .350 & .234 & .344 &. $\mathbf{7 4 7 \dagger}$ \\
\hline
\end{tabular}

Whereby a " $\dagger$ " indicates the average factor loadings.

\subsection{Structural model}

Structural equation modeling (SEM) method, particularly, partial least squares (PLS) analysis technique was used to validate the model. We decided to use this method because it is preferred when multiple valid indicators are available [61]. The choice of using PLS over other types of SEM techniques, e.g. covariance-based techniques, was determined by two main reasons: a) covariance-based technique has limitations when applied to exploratory studies and is primarily reputable as a confirmatory methodology; instead PLS technique shines forth in exploratory research; and b) the core of PLS estimation method ordinary least square - is very stable even at low sample sizes [61]. We used SmartPLS 2.0 with bootstrapping as a resampling technique (500 random samples) to test the structural model and the significance levels of the paths. Path coefficients, their significance levels, and the $R^{2}$ values were used jointly to evaluate the model.

Based on our hypotheses, we tested the impacts of data analytics infrastructure and IT-marketing social capital on exploratory and exploitative innovations. Data analytics infrastructure was found to positively affect exploratory $(\beta=0.451 ; \mathrm{t}=5.085)$ as well as exploitative innovations $(\beta=0.186 ; \mathrm{t}=4.949)$. ITmarketing social capital was positively associated with exploratory $(\beta=0.433 ; \mathrm{t}=2.616)$, but not exploitative innovations $(\beta=0.126 ; \mathrm{t}=1.476)$. Hence, with the exception of $\mathrm{H} 2 \mathrm{~b}$, all proposed hypotheses were supported (Figure 2).

\subsection{Common method bias}

Because the data were self-reported, common method bias (CMB) was a potential concern, which we address statistically in this section. We conducted the Harman's single-factor test [59]. We added all our dependent and independent variables to a principal component analysis without rotation and restricted the number of expected factors by 1 . The produced single factor provided explanation within the accepted range [60], which rejected the common method bias (CMB) assumption.

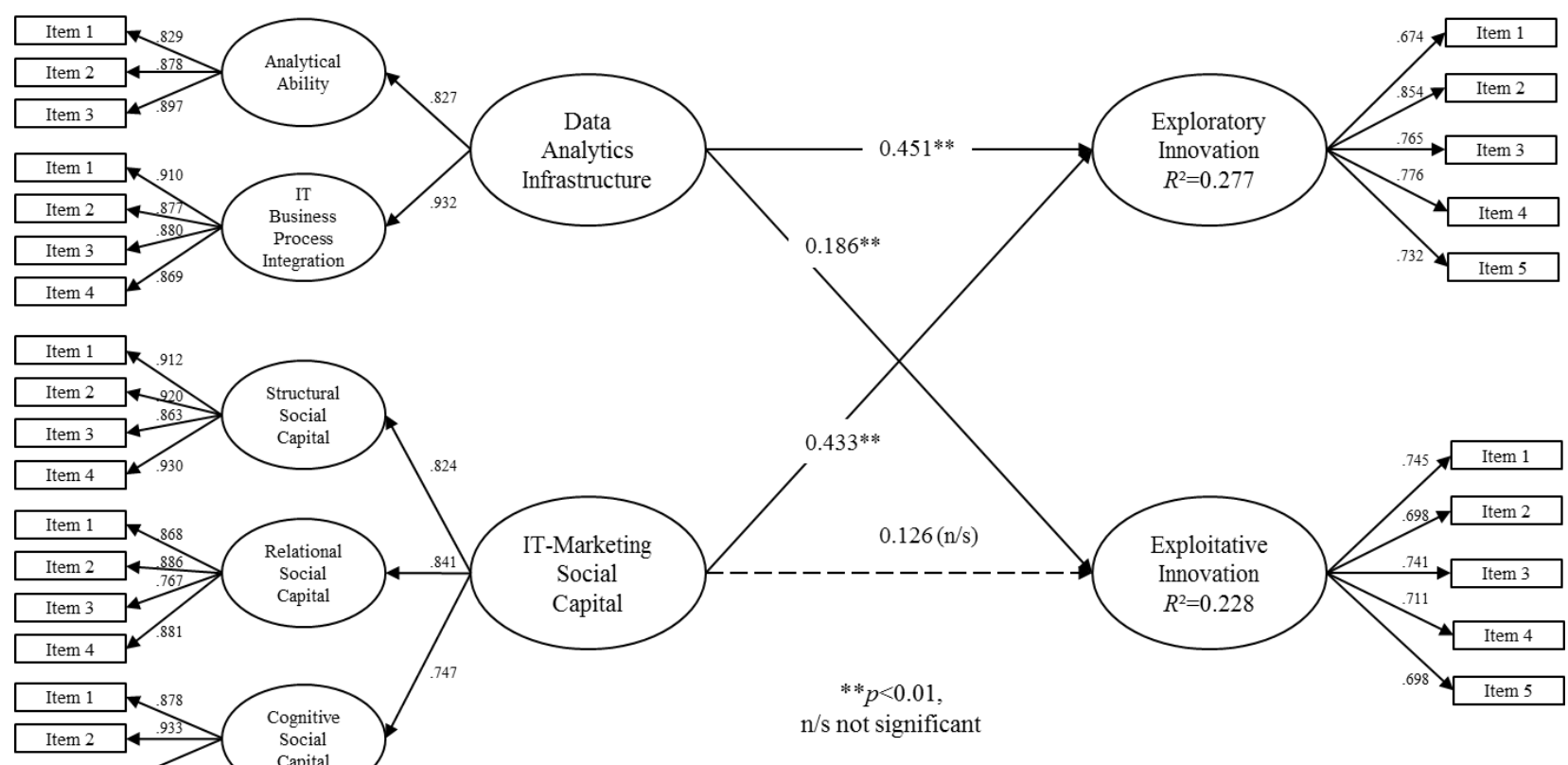

Figure 2. Results of the research model 


\section{Discussion and contributions}

\subsection{Discussion and theoretical contributions}

The key insight based on the study results is that data analytics infrastructure and IT-marketing social capital both intensify radical innovations in firms. This empirical result echoes the results from the body of research in the knowledge-based view that suggests that application of knowledge to produce products and/or services requires the bringing together of different areas of specialized knowledge [2]. The findings in this article, however, extend beyond the mere suggestion of predominantly established perspectives on the knowledge-based view in strategic management and makes contribution to knowledgebased view as well as to data analytics research by suggesting influence of a specific area of the knowledge end user that should be linked with data analytics practices, i.e. marketing functional unit. The particular relevance of marketing unit could be attributed to the transformative role that data analytics plays in marketing in the modern digital economy [44, 62]. Put differently, the need to involve customers in the product development process, getting feedback in real-time, a necessity to explore even (and especially) niche demands of those consumers whose tastes utterly deviate from "typical" customers' needs, and other marketing challenges find answers in crunching digital data that contain information about consumers' buying behavior, their changing needs, and their opinions about new and/or existing product features. Succeeding in these challenges indeed shows signs of disrupting the status quo in the set of deep assumptions about social events, and introducing a new perspective to the predominantly accepted linear reality.

An additional key insight suggested by the findings addresses the internal knowledge integration mechanism [10]. As empirical evidence suggests, informal social ties between IT and marketing functional units indeed play an important part in the radical innovation process. Drawing on social capital literature $[12,31]$, this result implies that it is strategically beneficial to encourage social interactions among the members of the IT and marketing functional units as well as the frequency of these interactions. Likewise, certain features of social relationships among these functional units, such as mutual respect, trust, appreciation and a high degree of reciprocity, contribute to increased sharing of data-driven insights with marketing units, which could later be applied to marketing challenges of a firm. Moreover, in this interfunctional interaction, the degree of comprehensibility in communication forms and language used might influence how effective the communication will be.
Applying social capital perspective to inter-unit relationships to gain the understating of the effect of social factors on knowledge exchange is not new. However, literature on data analytics has not yet referred to this perspective to examine to what extent such factors could influence sharing of data driven insight from the knowledge generator to the end user of these insights. These findings also theoretically contribute to knowledge-based view by give new meaning to earlier studies [13, 14], which proposes that knowledge integration mechanisms add complementary value to a firm's knowledge base by sharing and deploying this knowledge internally. Accordingly, the findings seem to demonstrate that previously discussed knowledge base within IT functional members, generated by the data analytics, can only be successfully deployed for innovation purposes in combination with the proposed knowledge sharing mechanism, i.e. IT-marketing social capital.

Lastly, referring to the hypothesis that was not supported $(\mathrm{H} 2 \mathrm{~b})$; possible explanations can lead to earlier studies on interpretive barriers to successful innovations [63]. Particularly, inter-departmental differences in interpretive schemes can become barriers to effective technology-market linkages.

\subsection{Practical contributions}

Study results propose a complex approach to the deployment of data analytics for innovation purposes. This means that managers interested in successfully deploying digital data resources need to not only embrace and integrate technical side of data analytics, but also its complementary resources. Particularly, as one of the main sources of external knowledge, managers should not only invest in modern data analytics tools, they also need to integrate these systems into business processes, so that these tools serve a new business opportunity detection process.

Additionally, informal social relationships prove to be an important contributing factor to the innovation process. Particularly, spurring IT and marketing functional units to engage in collaborative social activities could boost their social bonding, which seems to be a quintessential part of achieving successful radical innovations. A number of ways to achieve this bonding includes reducing physical distance between these units, engaging them in mutual social activities, and/or encouraging other socially collaborative efforts, among others.

\subsection{Limitations and future research}

In this study the arguments about the relationship between the technical perspective of data analytics and 
knowledge integration mechanism are based on theoretical arguments, i.e. we present the empirically supported effect of the two constructs on organizational innovations. What future studies could do is go one step further and empirically validate the two dimensional construct and test its aggregate effect on different innovation types as well as on other firm performance variables.

Future studies may also want to look deeper on the nature of the integration and explore different parts of process integration separately. Given the fact that process integration is an important part for data collection as well as knowledge dissemination, understanding the differences on these two sides might provide insightful results.

\section{Conclusion}

The aim of this study was to answer the following research question: "what is the knowledge integration mechanism in data analytics research, and to what extent does it affect the innovative performance of a firm?"

To address the question we conducted an online survey and tested proposed hypotheses with empirical results. With the findings of the study, we proposed ITmarketing social capital as an important mechanism of knowledge integration in a firm. Additionally, we identified that data analytics infrastructure has a positive effect on radical as well as incremental innovations, while IT-marketing social capital is positively influencing only radical innovations in firm.

With these findings, the article empirically shows that intraorganizational social relationships can be viewed as an effective mechanism for knowledge integration that could facilitate desired organizational performance.

By shedding more light on data analytics literature from the theoretical lens of social capital, particularly by proposing channels of knowledge flows from the knowledge provider (data analytics) to the knowledge seeker (marketing); the findings of the presented manuscript make contributions not only to data analytics literature [4-8], but also to social capital [11, $12,30,31]$ as well as knowledge-based view [2, 3, 15].

\section{Appendix. Survey measurements}

\section{Analytical Ability}

Item 1 - We have IT applications that offer various simulation and what-if analysis tools for managing our relationships with customers.

Item 2 - We have IT applications that offer various decision-making tools (e.g. ad hoc query tools, data mart, DBMS, ETL, OLAP, dashboard applications, visualization tools, Hadoop- and MapReduce-based systems) for managing our relationships with customers.

Item 3 - We have IT applications that offer various tools that enable us to examine trends in the data for supporting our interactions with customers.

\section{IT Business Process Integration}

Item 1 - We always merge business processes using IT to leverage opportunities.

Item 2 - We continually restructure our business processes using IT in order to exploit new business opportunities.

Item 3 - We always integrate IT in our business processes to leverage opportunities.

Item 4 - Our IT integrated into business processes allows us to leverage business opportunities.

\section{Structural Social Capital}

Item 1 - Employees from marketing and IT departments maintain close social relationships with each other.

Item 2 - Employees from marketing and IT departments spend a lot of time interacting with each other.

Item 3 - Employees from marketing and IT departments know each other at a personal level.

Item 4 - Employees from marketing and IT departments have frequent communication with each other.

\section{Relational Social Capital}

Item 1 - The relationship between employees from marketing and IT departments is characterized by mutual respect.

Item 2 - The relationship between employees from marketing and IT departments is characterized by mutual trust.

Item 3 - The relationship between employees from marketing and IT departments is characterized by high reciprocity.

Item 4 - The relationship between employees from marketing and IT departments is characterized by mutual appreciation.

\section{Cognitive Social Capital}

Item 1 - When interacting, employees from marketing and IT departments use common terms or jargon. Item 2 - During the discussions, employees from marketing and IT departments use understandable communication pattern.

Item 3 - When communicating, employees from marketing and IT departments use understandable narrative forms.

\section{Exploratory Innovation}

Item 1 - Our company accepts demands that go beyond existing products and services.

Item 2 - We invent new products and services. 
Item 3 - We experiment with new products and services in our local market.

Item 4 - We commercialize products and services that are completely new to our company.

Item 5 - We frequently utilize new opportunities in new markets.

\section{Exploitative Innovation}

Item 1 - We frequently refine the provision of existing products and services.

Item 2 - We introduce improved, but existing products and services for our local market.

Item 3 - We improve our provision's efficiency of products and services.

Item 4 - We increase economies of scales in existing markets.

Item 5 - Our company expands services for existing clients.

\section{References}

[1] H. Tsoukas, "The firm as a distributed knowledge system: A constructionist approach," Strategic Management J., vol. 17, no. S2, pp. 11-25, 1996.

[2] R. M. Grant, "Prospering in dynamically-competitive environments: Organizational capability as knowledge integration," Org. Science, vol. 7, no. 4, pp. 375-387, 1996.

[3] R. M. Grant, "Toward a knowledge-based theory of the firm," Strategic Management J., vol. 17, no. S2, pp. 109122, 1996.

[4] Y. Yoo, O. Henfridsson, and K. Lyytinen, "Research commentary: The new organizing logic of digital innovation: An Agenda for Information Systems Research," Inf. Systems Research, pp. 724-735, 2010,

[5] R. Agarwal and V. Dhar, "Editorial - Big Data, data science, and analytics: The opportunity and challenge for IS research," Inf. Systems Research, vol. 25, no. 3, pp. 443-448, 2014.

[6] H. Chen, Chiang, R. H. L., and Storey, V. C., "Business intelligence and analytics: From Big Data to Big Impact," MIS Quarterly, vol. 36, no. 4, pp. 1165-1188, 2012.

[7] P. B. Goes, "Big Data and IS research," MIS Quarterly, vol. 38, no. 3, pp. 3-8, 2014.

[8] V. Sambamurthy and R. W. Zmud, "Research commentary: The organizing logic for an enterprise's IT activities in the Digital Era - A prognosis of practice and a call for research," Inf. Systems Research, vol. 11, no. 2, pp. 105-114, 2000.

[9] G. D. Bhatt and V. Grover, "Types of information technology capabilities and their role in competitive advantage: An empirical study," J. of Management Inf. Systems, vol. 22, no. 2, pp. 253-277, 2005.

[10]L. de Luca and K. Atuahene-Gima, "Market knowledge dimensions and cross-functional collaboration: Examining the different routes to product innovation performance," J. of Marketing, vol. 71, no.1, pp. 95-112, 2007.

[11]J. Nahapiet and S. Ghoshal, "Social capital, intellectual capital, and the organizational advantage," Academy of Management Review, vol. 23, no. 2, pp. 242-266, 1998.
[12]W. Tsai and S. Ghoshal, "Social capital and value creation: The role of intrafirm networks," Academy of Management J., vol. 41, no. 4, pp. 464-476, 1998.

[13]G. Verona, "A resource-based view of product development," Academy of Management Review, vol. 24, no. 1, pp. 132-142, 1999.

[14]K. Z. Zhou and C. B. Li, "How knowledge affects radical innovation: Knowledge base, market knowledge acquisition, and internal knowledge sharing," Strategic Management J., vol. 33, no. 9, pp. 1090-1102, 2012.

[15]M. Alavi and D. E. Leidner, "Review: Knowledge management and knowledge management systems: Conceptual foundations and research issues," MIS Quarterly, pp. 107-136, 2001.

[16]G. George, M. R. Haas, and A. Pentland, "Big Data and Management," Academy of Management J., vol. 57, no. 2, pp. 321-326, 2014.

[17]A. McAfee and E. Brynjolfsson, "Big Data: The management revolution," Harvard Business Review, vol. 90, no. 10, pp. 60-68, 2012.

[18]A. Shollo and R. D. Galliers, "Towards an understanding of the role of business intelligence systems in organisational knowing," Inf. Systems J., vol. 26, no 4, pp. 339-367, 2015.

[19]P.Tambe, "Big data investment, skills, and firm value," Management Science, vol. 60, no. 6, pp. 1452-1469, 2014.

[20]D. Boyd and K. Crawford, "Critical questions for big data: Provocations for a cultural, technological, and scholarly phenomenon," Information, Communication \& Society, vol. 15, no. 5, pp. 662-679, 2012.

[21]V. Dhar, "Data science and prediction," Communications of the ACM, vol.56, no.12, pp. 64-73, 2013.

[22]O. Müller, I. Junglas, J. Vom Brocke, and S. Debortoli, "Utilizing Big Data analytics for information systems research: challenges, promises and guidelines," European J. of Inf. Systems, vol. 25, no. 4, pp. 289-302, 2016.

[23]Y. Yoo, "It is not about size: a further thought on Big Data," J. of Inf. Technology, vol. 30, no. 1, pp. 63-65, 2015.

[24]I. Hendel and A. Nevo, "Measuring the implications of sales and consumer inventory behavior," Econometrica, vol. 74, no. 6, pp. 1637-1673, 2006.

[25]A. Nevo and C. Wolfram, "Why do manufacturers issue coupons? An empirical analysis of breakfast cereals," RAND J. of Economics, pp. 319-339, 2002.

[26]T. H. Davenport, J. G. Harris, and R. Morison, Analytics at work: Smarter decisions, better results: Harvard Business Press, 2010.

[27]T. H. Davenport and J. G. Harris, Competing on analytics: The new science of winning: Harvard Business Press, 2007.

[28]R. Sharma, S. Mithas, and A. Kankanhalli, "Transforming decision-making processes: a research agenda for understanding the impact of business analytics on organisations," European J. of Inf. Systems, vol. 23, no. 4, pp. 433-441, 2014.

[29]J. Luftman et al., "Key information technology and management issues 2011-2012: an international study," J. of Information Technology, vol. 27, no. 3, pp. 198-212, 2012.

[30]W. Tsai, "Social capital, strategic relatedness and the formation of intraorganizational linkages," Strategic Management J., pp. 925-939, 2000. 
[31]W. Tsai, "Knowledge transfer in intraorganizational networks: Effects of network position and absorptive capacity on business unit innovation and performance," The Academy of Management J., vol.44, no.5, pp.996-1004, 2001.

[32]M. J. Benner and M. L. Tushman, "Exploitation, exploration, and process management: The productivity dilemma revisited," Academy of Management Review, vol. 28, no. 2, pp. 238-256, 2003.

[33]J. J. P. Jansen, Van Den Bosch, Frans AJ, and H. W. Volberda, "Exploratory innovation, exploitative innovation, and performance: Effects of organizational antecedents and environmental moderators," Management Science, vol. 52, no. 11, pp. 1661-1674, 2006.

[34]J. G. March, "Exploration and exploitation in organizational learning," Org. Science, vol. 2, no. 1, pp. 7187, 1991.

[35]C. A. O'Reilly and M. L. Tushman, "Ambidexterity as a dynamic capability: Resolving the innovator's dilemma," Research in Org. Behavior, vol. 28, pp. 185-206, 2008.

[36]M. J. Benner and M. Tushman, "Process management and technological innovation: A longitudinal study of the photography and paint industries," Administrative Science Quarterly, vol. 47, no. 4, pp. 676-707, 2002.

[37]S. Chaudhuri, U. Dayal, and V. Narasayya, "An overview of business intelligence technology," Communications of the ACM, vol. 54, no. 8, pp. 88-98, 2011.

[38]B. Dehning and V. J. Richardson, "Returns on investments in information technology: A research synthesis," J. of Inf. Systems, vol. 16, no. 1, pp. 7-30, 2002.

[39]N. Melville, K. Kraemer, and V. Gurbaxani, "Review: Information technology and organizational performance: An integrative model of IT business value," MIS Quarterly, vol. 28, no. 2, pp. 283-322, 2004.

[40]S. Nevo, M. R. Wade, and W. D. Cook, "An examination of the trade-off between internal and external IT capabilities," J. of Strategic Inf. Systems, vol. 16, no. 1, pp. 523, 2007.

[41]S. Nevo and M. R. Wade, "The formation and value of IT-enabled resources: Antecedents and consequences of synergistic relationships," MIS Quarterly, vol. 34, no. 1, pp. 163-183, 2010.

[42]A. Radhakrishnan, X. Zu, and V. Grover, "A processoriented perspective on differential business value creation by information technology: An empirical investigation," Omega, vol. 36, no. 6, pp. 1105-1125, 2008.

[43]N. Wang, H. Liang, W. Zhong, Y. Xue, and J. Xiao, "Resource Structuring or Capability Building? An Empirical Study of the Business Value of Information Technology," $J$. of Management Inf. Systems, vol. 29, no. 2, pp. 325-367, 2012.

[44]S. Erevelles, N. Fukawa, and L. Swayne, "Big Data consumer analytics and the transformation of marketing," $J$. of Business Research, vol. 69, no. 2, pp. 897-904, 2016.

[45]F. Acito and V. Khatri, "Business analytics: Why now and what next?," Business Horizons, vol. 57, no. 5, pp. 565570, 2014.

[46]R. Y. Du, Y. Hu, and S. Damangir, "Leveraging trends in online searches for product features in market response modeling," J. of Marketing, vol. 79, no. 1, pp. 29-43, 2015.

[47]S. Tirunillai and G. J. Tellis, "Mining marketing meaning from online chatter: Strategic brand analysis of big data using latent dirichlet allocation," J. of Marketing Research, vol. 51, no. 4, pp. 463-479, 2014.

[48]G. Verona and D. Ravasi, "Unbundling dynamic capabilities: An exploratory study of continuous product innovation," Industrial and Corporate Change, vol. 12, no. 3, pp. 577-606, 2003.

[49]S. A. Sivo, C. Saunders, Q. Chang, and J. J. Jiang, "How low should you go? Low response rates and the validity of inference in IS questionnaire research," J. of the Association for Inf. Systems, vol. 7, no. 6, pp. 351-414, 2006.

[50]N. Roberts and V. Grover, "Leveraging information technology infrastructure to facilitate a firm's customer agility and competitive activity: An empirical investigation," J. of Management Inf. Systems, vol. 28, no. 4, pp. 231-270, 2012.

[51]A. S. Bharadwaj, V. Sambamurthy, and R. W. Zmud, Eds., IT capabilities: theoretical perspectives and empirical operationalization: Association for Inf. Systems, 1999.

[52]Y. Sun, Y. Fang, K. H. Lim, and D. Straub, "User satisfaction with information technology service delivery: A social capital perspective," Inf. Systems Research, vol. 23, no. 4, pp. 1195-1211, 2012.

[53]J. E. Gerow, J. B. Thatcher, and V. Grover, "Six Types of IT-Business Strategic Alignment: An investigation of the constructs and their measurement," European J. of Inf. Systems, vol. 24, no. 5, pp. 465-491, 2014.

[54] S. Petter, D. Straub, and A. Rai, "Specifying formative constructs in information systems research," MIS Quarterly, pp. 623-656, 2007.

[55]L. Hu and P. M. Bentler, "Cutoff criteria for fit indexes in covariance structure analysis: Conventional criteria versus new alternatives," Structural Equation Modeling: A Multidisciplinary J., vol. 6, no. 1, pp. 1-55, 1999.

[56]G. Churchill, "A paradigm for developing better measures of marketing constructs," J. of Marketing Research, pp. 64-73, 1979.

[57]J. F. Hair, Multivariate data analysis, 2010.

[58]J. Nunnally, C. Psychometric theory: New York: McGraw-Hill, 1978.

[59]P. M. Podsakoff and D. W. Organ, "Self-reports in organizational research: Problems and prospects," $J$. of Management, vol. 12, no. 4, pp. 531-544, 1986.

[60]H. H. Harman, Modern factor analysis: University of Chicago Press, 1976.

[61]D. Gefen, D. W. Straub, and E. E. Rigdon, “An update and extension to SEM guidelines for admnistrative and social science research," MIS Quarterly, vol. 35, no. 2, pp.3-14, 2011.

[62]Z. Xu, G. L. Frankwick, and E. Ramirez, "Effects of Big Data analytics and traditional marketing analytics on new product success: A knowledge fusion perspective," $J$. of Business Research, vol. 69, no. 5, pp. 1562-1566, 2016.

[63] D. Dougherty, "Interpretive barriers to successful product innovation in large firms". Org. Science, vol. 3, no. 2, pp. 179-202, 1992

[64] O. Müller, I. Junglas, J. vom Brocke, and S. Debortoli, "Utilizing big data analytics for information systems research: Challenges, promises and guidelines," European J. of Inf. Systems, vol. 25, no. 4, pp. 289-302, 2016. 